\title{
MIGRATION AND THE SMALLER COMMUNITY
}

\author{
Wayne W. McVey, Jr. \\ University of Alberta, Edmonton, Alberta, Canada
}

Résumé - Le but de cette étude est de vérifier les principaux caractères des populations d'émigrants internes et d'immigrants qui se déplacent ver les plus petite et les plus grandes communautés en Alberta afin de déterminer en quelle façon leurs caractères diffèrent de ceux des non-émigrants. Utilisant les données du rencesement de sondage enregistré pour l'usage public de 1971, on note que les conclusions révèlent des différences importantes entre les états non-émigrants les états migrants. Et les émigrants internes et les immigrants sont susceptibles d'être plus éduqués, d'avoir des professions plus importantes et des familles moins nombreuses que les non-émigrants des communautés accueillantes. Quant aux petites communautés, les caractères d'immigration différèrent d'une manière significative de celles des non-émigrants. De plus, il est évident que la structure d'âge de la population des non-émigrants plus âgés dans les plus petites communautés est en contraste marqué avec la structure d'âge des populations migrantes moins âgées.

Abstract - The purpose of this paper is to ascertain the major characteristics of the in-migrant and the immigrant populations who move to smaller and larger communities in Alberta and to determine in what way their characteristics differ from those of the non-migrants. Using 1971 Public Use Sample Tape census data, the findings reveal significant differences between the non-migrant and migrant statuses. Both in-migrants and immigrants tend to have more education, higher status occupations, and smaller family size than the non-migrants of the receiving communities. For the smaller communities, the immigrant characteristics differed significantly from those of the non-migrants. In addition, it is evident that the older age structure of the non-migrant population in small communities is in sharp contrast to the younger age structure of the migrant populations.

\section{Key Words - migration; small communities; migration differentials}

Historically, the main contributor to the population growth of urban places in Canada has been the youthful migrant participating in the traditional rural-to-urban migration stream. While migration continues to play an important role in the process of urbanization, the migration pattern has shifted. The former importance of rural-to-urban migration has given way to an inter-urban pattern of migration (Stone, 1969). Recent metropolitan growth in Canada has resulted, in part, from this inter-urban migration.

Since the turn of the century, the pattern of migration flows within Canada have shifted according to the emergence of new economic patterns. Development of the wheat economy between 1900 and 1920 had encouraged the establishment of rural settlements in the previously unsettled Prairie Provinces. The stimulus of a new federal agricultural policy, along with the completion of a trans-Canada rail system and high immigration, served to forge a stabilized agricultural economic base in the nation. The internal migration pattern reached a turning point during the 1920 s, whereupon the more traditional rural-to-urban flow of migrants began and accelerated over the following 40 years. During this period, the net movement out of farm areas was 3.2 million people and the net movement into non-farm areas was 4.6 million and the major proportion of the 
Wayne W. McVey, Jr.

latter movement was into urban areas (Anderson, 1966:16). With the exception of the Depression years (1931-1940), the net migration out of rural areas had been consistently rapid and the rate of net migration out of farm areas had increased very substantially (Anderson, 1966:17). The surplus rural manpower brought about by improved agricultural technology competed with the immigrant labour sources in the urban centres of Canada.

Although over three-fourths of the Canadian population resided in urban places in 1971, the rural-to-urban movement was still in evidence. Internal migration data reported in the 1971 Census of Canada by type of movement indicate that rural-to-urban migrants numbered 585,130, or only 16 per cent of total migrants. As indicated in Table 1 , inter-urban migration has become the predominant movement with over two and one-quarter million migrants, or about 64 per cent of the total number of migrants. The methodological difficulty encountered in interpreting the inter-urban migration data is that it is not possible to distinguish which direction this type of migration is taking, i.e., whether from smaller to larger or larger to smaller urban places.

When considering the two most recent census migration periods - 1956-1961 and 1966-1971 - it is evident that the number of migrants from farm areas to non-farm and urban destinations had declined considerably. Conversely, the number of migrants from urban areas to rural farm and non-farm areas had increased over the two census periods. Non-farm migrants to urban areas accounted for the major share of the rural-to-urban migration stream in 1971 - an increase of 180 per cent from the 1961 migration period. Farm to urban migrants accounted for over 9 per cent of the total movement in 1961; however, by 1971 this proportion declined to 4 per cent.

Ruralward migration increased over the two census periods from 494,734 in 1961 to 562,095 in 1971, representing an increase of over 13 per cent. On the other hand, urbanward migrants increased by 46,976 between 1961 and 1971, or an 8 per cent change. The net urbanward movement was only 25,035 migrants in 1971 as a result of the greater increase in the ruralward movement since 1961.

TABLE 1. NUMBER OF INTERNAL MIGRANTS BY TYPE OF MOVEMENT, CANADA: 1956-1961 AND 1966-1971

\begin{tabular}{lrrrr}
\hline Type of Movement & $1956-1961$ & $1966-1971$ & Difference & $\begin{array}{r}\text { Per Cent } \\
\text { Change }\end{array}$ \\
\hline Rural to Urban: & 538,154 & 585,130 & 46,976 & 8.7 \\
$\begin{array}{l}\text { non-farm to urban } \\
\text { farm to urban }\end{array}$ & 141,507 & 396,560 & 255,053 & 180.2 \\
farm to non-farm & 244,278 & 153,750 & $-90,528$ & -37.1 \\
Urban to Rural: & 152,369 & 34,820 & $-117,549$ & -77.2 \\
urban to non-farm & 494,734 & 562,095 & 67,361 & 13.6 \\
urban to farm & 371,711 & 399,005 & 27,294 & 7.3 \\
non-farm to farm & 75,075 & 125,250 & 50,175 & 66.8 \\
$\quad$ & 47,948 & 37,840 & $-10,108$ & -21.1 \\
Circular Movement: & $1,552,521$ & $2,434,500$ & 881,979 & 56.8 \\
urban to urban & $1,467,326$ & $2,281,080$ & 813,754 & 55.5 \\
non-farm to non-farm & 65,287 & 125,270 & 59,983 & 91.9 \\
farm to farm & 19,908 & 28,150 & 8,242 & 41.4 \\
Total Internal Migrants: & $2,585,409$ & $3,581,725$ & 996,316 & 38.5 \\
\hline
\end{tabular}

Source: Dominion Bureau of Statistics. 1961 Census of Canada, Bulletin 4.1-9, Ot tawa: The Queen's Printer, 1965, Tables 12 and 13; and Statistics Canada. 1971 Census of Canada, Bulletin 1.2-7, Ot tawa: Information Canada, 1974, Table 33 . 
While migrants from farm to urban and non-farm areas have diminished in number and proportionately over the two census periods and the importance of inter-urban migration has increased, it is equally important to recognize the emergence of the urban movement to rural farm and non-farm destinations. Part of this urban ta rural migration is a consequence of the normal growth pattern of large urban places. It is evident that internal migration over the past 20 years has involved the redistribution of population among different sized urban places, rather than simply rural-to-urban movement as it had been in the past (Gertler and Crowley, 1977; Lamont and Proudfoot, 1975; Stone, 1968).

Concern has been demonstrated recently for a third migration stream that has been increasing in importance. This counterstream flow has already been observed in the United States as a metropolitan-to-non-metropolitan movement. According to DeJong and Humphrey, recent estimates revealed that more people had left metropolitan areas than had arrived (DeJong and Humphrey, 1976). In addition, as a consequence of the decentralization of urban populations and the initiation of resource development outside metropolitan areas, the urban-to-rural movement is increasing in magnitude (Kirschenbaum, 1971). The outcome of rural resource development would be changes in the occupational structure of potential rural receiving areas. Improvements in transportation and communication networks in the United States have contributed to the urban-to-rural migration stream through the reduction of time-cost factors, i.e., the time and cost aspects of commuting from place of residence to place to work have been reduced, thus allowing the distance to be increased without measurably increasing these costs. In addition, many of the larger urban centres are already heavily populated and individual dissatisfaction with these larger urban complexes had provided further inducements for this counterstream.

The concern of this research is the movement of people to smaller communities as a component of the larger urban-to-rural migration stream. It is known that migration will have an impact upon the sending areas as well as the receiving area. As noted by Bogue, migration reflects basic social change (Bogue, 1959). The attraction of newcomers to an area may be precipitated by improved occupational opportunities brought about by the exploration for and development of new resources, the relocation of service and manufacturing industries, and governmental efforts to revitalize the older, smaller communities. These factors may generate large in-migrant streams of workers and their dependents. In this manner, internal migration becomes a mechanism for efficiently utilizing manpower resources and could be used as a regulatory instrument for controlling migration's redistributive effects (Bogue, 1959). In other words, if the volume of migration cannot be directly controlled, the effects of migration may be regulated by manipulating the factors that influence the movement of people.

The consequences of a rapid influx of migrants to smaller communities can be quite dramatic from social and economic perspectives, particularly if the volume of migrants is high and their characteristics are quite dissimilar to the community's receiving population's. While researchers and governments alike have expressed concern for the economic viability of the smaller community, neither have had adequate data to examine the potential effects of significantly dissimilar populations in juxtaposition (United Nations, 1975; Wardell, 1977; Graber, 1974). To assist policy makers in anticipating and assessing the social and economic impact of an influx of migrants upon a receiving area, it would be beneficial to have knowledge of their major social and economic characteristics. As Petersen noted, migrants are likely to reflect, in their characteristics, the basic social and economic changes that are taking place in the receiving community (Petersen, 1969).

The availability of individual and household data through the Public Use Sample 
Wayne W. McVey, Jr.

Tapes in the United States has enabled researchers to examine the selective character of migration (DeJong and Humphrey, 1976; Kirschenbaum, 1971). Migrants are not representative of the population they leave or the population to which they move, and it is evident from the migration literature that the migrant differs significantly from the non-migrant (Goldscheider, 1971). Earlier surveys concerned with the selective character of migration have found that the migrant in comparison with either the sending or receiving area population tended to be younger, have a higher education, be in a professional occupation, and be male (Bogue, 1959; Shryock, 1964; Goldscheider, 1971). In a study of counterstream migrant household heads, DeJong and Humphrey found that metropolitan-to-non-metropolitan migrant heads tended to be younger, have a higher education, have a smaller household size, and be of a higher socio-economic status than the migrant heads in the non-metropolitan-to-metropolitan migration stream. They concluded that the arrival of these younger migrants of higher socio-economic status could have profound consequences for the social organization and stratification system of the receiving community, as well as placing immediate strains upon the existing service network of the community (DeJong and Humphrey, 1976).

Utilizing 1971 Census of Canada migration data, this study explores the following research questions for the province of Alberta. First, what are some of the major characteristics of the in-migrant and immigrant population moving to smaller communities as opposed to those moving to larger communities, and, second, in what way do the in-migrant and immigrant characteristics differ from the non-migrant characteristics in the receiving communities?

\section{Methodology}

This research uses 1971 census data retrieved from the individual file of the Public Use Sample Tapes made available through the Population Research Laboratory, University of Alberta. The categories for which census data are available permit the present research to explore the selective character of both in-migrants and immigrants to communities of less than 30,000 inhabitants and to communities of more than 30,000 . The Public Use Sample Tapes restrict data availability to only these community size aggregations. The analysis is restricted to Alberta migration data only. The Province of Alberta provides an opportunity to study a receiving area for migration in that it was experiencing a growth economy and low unemployment at the time of the 1971 Census. In addition, the provincial government has expressed considerable interest in the economic viability and survival of the smaller community (Environment Conservation Authority, 1976).

By cross-tabulating migration status characteristics on place of residence in 1966 with place of residence in 1971, individual records were collapsed to the following migration statuses: ${ }^{1}$

1. Non-migrants - individuals who had occupied the same dwelling or had changed dwelling units within the same community over the five-year migration period, 1966-1971.

2. In-migrants - individuals whose place of residence five years prior to the 1971 census date was outside the municipality in which they were residing at the census date, but within Canada.

3. Immigrants - individuals who were residing outside Canada five years prior to the 1971 census date.

Migration status characteristics by place of residence were retrieved for communities less than and more than 30,000 population size. For Alberta, communities with over 
30,000 inhabitants include Edmonton, Calgary, and Lethbridge, and all of the remaining communities in the province had between 1,000 and 30,000 inhabitants. The characteristics selected for this analysis include number of children as an indicator of family size, number of intermunicipal moves, occupation, level of education, and marital status. Age by migration status is analyzed for the smaller community size category only. ${ }^{2}$ Selection of these characteristics was made on the basis of the major findings reported in the United States migration literature (DeJong and Humphrey, 1976; Kirschenbaum, 1971).

The census distinction between the non-migrant, in-migrant, and immigrant is based on a conceptual definition of migration. Migration involves a complete change of residence in which the migrant and immigrant would likely be confronted with a new social network and organization in the receiving area that they would have to adjust to. The non-migrants as noted include the individual whose residence remained the same over the five-year migration period and the individual who changed residence within the same community. Hence, the non-migrant category consists of the permanent residents and the local movers. In comparison to the in-migrant and the immigrant, the local mover is not as likely to experience any dramatic change in the local community's social structure.

The in-migrant and immigrant, however, will experience a severance of former community ties. In movement to a new community, the migrant and immigrant will be confronted with adjustment to a different social structure and stratification system, and perhaps a change in living arrangements. It was felt that for this research it would be fruitful to analyze in-migrants and immigrants separately. Previous migration research in the analysis of differential migration had not distinguished between the internal migrant and immigrant. It would be important to determine if the migrant and immigrant characteristics are equally dissimilar or different from the non-migrant characteristics. It is important to recognize that the immigrant category would include immigrants from countries with similar cultures to that of Canada, as well as countries with quite different cultures.

In the analysis, indices of dissimilarity were computed. The dissimilarity index allows for the comparison of each characteristic of the different classes of migrants for each community size category. The difference or degree of dissimilarity between the classes of migrants is then represented by the index (Shryock and Siegal, 1973:232-233). The index of dissimilarity is a summary measure of the difference between two distributions and is based on the absolute differences between the per cents at each interval of the distributions. Accordingly, the differences between the per cents for corresponding intervals of the distributions are determined; they are summed without regard to sign, and one-half the sum is taken. The computational formula for the index of dissimilarity is then:

$$
\text { Index of dissimilarity }=\frac{1}{2} \sum\left|r_{2 \mathrm{a}}-r_{1 \mathrm{a}}\right|
$$

Since the data generated from the Public Use Summary Tapes are based on a one per cent sample of all individual files, significant differences were tested using a z-test.

The normal cautions in using and interpreting census data on migrants are worth noting at this time. Local movers, who are included in the non-migrant category, could conceivably move from their 1966 census residence to another municipality and return to their former residence by the time of the 1971 census and, therefore, be erroneously classified as a non-migrant when actually they have made an intermunicipal move. It is assumed, however, that this phenomenon would not be frequent enough to distort the 
Wayne W. McVey, Jr.

findings. Furthermore, for those who did change residence, the timing of the move within the migration period is not discernible from the census data, in that the migrant may have moved in either the latter part of 1966 or the first part of 1971. The change of residence could have occurred at any time during the five-year census migration period.

Another caution to consider would be that the characteristics of the migrants are those indicated after the migration has taken place. For example, an individual could have changed residence in 1967 with little education at that time. However, by 1971 the same migrant could have achieved a higher level of educational attainment. Similarly, the immigrant who arrives in Canada in 1968, lives in Toronto until 1970, and then migrates to a small community in Alberta just prior to the 1971 Census is classified as an immigrant in the census but conceptually has been active as an in-migrant prior to the census date.

\section{Migration Differentials by Community Size}

The indices of dissimilarity comparing the data distributions for in-migrants and immigrants with the non-migrants for communities over 30,000 population size reveal that the immigrants are more dissimilar than the migrant group with respect to education level. As indicated in Table 2, the immigrant group evinces somewhat higher dissimilarity indices on the occupational and marital status dimensions and a markedly higher index on educational level than the in-migrant group. In other words, the immigrant population is more dissimilar than the in-migrant population with respect to the educational level of the household head. The in-migrant group is more dissimilar from the non-migrant group with respect to number of intermunicipal moves than the immigrant group. This disparity between the indices for in-migrants and immigrants would be expected, in that immigrants (29.6) would likely make their major personal investment in a single, long-distance move over the migration period whereas in-migrants (94.6) would likely be engaged in several shorter distance moves. The difference in educational characteristics between the in-migrant and immigrant group is likely influenced by the exacting admission requirements dictated by Canadian immigration policy.

As observed in Table 2, the immigrant and in-migrant differ significantly from the non-migrant group in terms of family size (as measured by number of children) and occupational structure. Accordingly, both the immigrant and in-migrant groups tend to be characterized by smaller family size and professional, managerial, and technical occupational endeavours in comparison to the non-migrant population. These findings are consistent with the educational differentials for the two migrant groups, in that the more highly educated migrant would likely seek higher level positions in the occupational structure and opt for smaller family size. Both the in-migrant and immigrant groups manifest higher proportions married than do non-migrants, but there is no significant difference shown in the marital status of the two migrating groups. There is general agreement with the literature on migration differentials, since both in-migrants and immigrants tend to have more education, higher status occupations, and smaller family size than the non-migrant group of the receiving community. Noteworthy is the greater dissimilarity of the immigrant group's educational level.

In examination of the movement of in-migrants and immigrants to communities of less than 30,000 inhabitants, it is evident that there is a marked difference between dissimilarity indices. The immigrant group is more dissimilar than the in-migrant group with respect to all characteristics with the exception of inter-municipal moves. The in-migrants are less dissimilar from the non-migrants of receiving communities on the 
TABLE 2. PERCENTAGE DISTRIBUTION OF SELECTED CHARACTERISTICS BY MIGRATION STATUS AND DISSIMILARITY INDICES' FOR COMMUNITIES UNDER 30,000 INHABITANTS AND OVER 30,000 INHABITANTS, ALBERTA: 1971

\begin{tabular}{|c|c|c|c|c|c|c|}
\hline \multirow{2}{*}{$\begin{array}{c}\text { Selected } \\
\text { Characteristic }\end{array}$} & \multicolumn{3}{|c|}{ Communities Under 30,000} & \multicolumn{3}{|c|}{ Communities Over 30,000} \\
\hline & $\begin{array}{l}\text { Non- } \\
\text { Migrants }\end{array}$ & $\begin{array}{c}\text { In- } \\
\text { Migrants }\end{array}$ & Immigrants & $\begin{array}{c}\text { Non- } \\
\text { Migrants }\end{array}$ & Migrants & Immigrants \\
\hline
\end{tabular}

Occupational Status

Managerial, Pro-
fessional, Tech..... $16.5 \%$
Clerical, Sales.... $38.5 \%$
Farming, Primary.... $5.4 \%$
Other, Not Stated... 22.6\%
Dissimilarity Index..
Marital Status

\begin{tabular}{|c|c|}
\hline 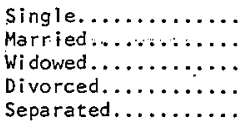 & $\begin{array}{r}43.2 \% \\
46.9 \% \\
7.0 \% \\
1.2 \% \\
1.6 \%\end{array}$ \\
\hline Dissimilarity Index. & \\
\hline Children Ever Born & \\
\hline
\end{tabular}

$\begin{array}{cc}20.8 \% & 29.5 \% \\ 38.0 \% & 42.6 \% \\ 6.3 \% & 4.9 \% \\ 21.0 \% & 13.1 \% \\ 5.3 & 17.2\end{array}$

$\begin{array}{ccc}17.8 \% & 25.3 \% & 28.8 \% \\ 44.7 \% & 44.7 \% & 38.8 \% \\ 1.7 \% & 3.3 \% & 1.1 \% \\ 20.8 \% & 18.5 \% & 21.6 \% \\ & 9.2 & 11.8\end{array}$

$\begin{array}{ll}42.7 \% & 33.0 \% \\ 50.8 \% & 62.8 \% \\ 2.9 \% & 3.2 \% \\ 1.8 \% & 1.1 \% \\ 1.8 \% & 0.0 \% \\ 4.7 & 15.8\end{array}$

$\begin{array}{rrr}42.8 \% & 43.6 \% & 41.3 \% \\ 48.3 \% & 50.0 \% & 52.9 \% \\ 4.9 \% & 1.6 \% & 3.2 \% \\ 2.4 \% & 1.9 \% & 1.7 \% \\ 1.6 \% & 2.9 \% & 0.9 \% \\ & 3.8 & 4.6\end{array}$

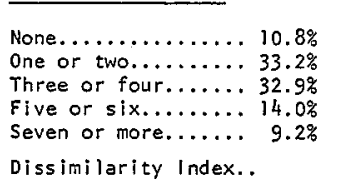

$\begin{array}{cc}22.6 \% * & 27.0 \% \\ 43.8 \% * & 43.2 \% \\ 24.0 \% & 18.9 \% \\ 11.1 \% & 8.1 \% \\ 8.8 \% & 2.7 \% \\ 16.2 & 26.3\end{array}$

$\begin{array}{ccc}14.4 \% & 24.3 \% & 22.8 \% \\ 39.5 \% & 43.1 \% & 43.9 \% \\ 32.3 \% & 22.3 \% & 28.5 \% \\ 9.9 \% & 7.8 \% & 4.1 \% \\ 4.0 \% & 2.4 \% & 0.8 \% \\ & 13.6 & 12.8\end{array}$

Inter-Municipal Moves

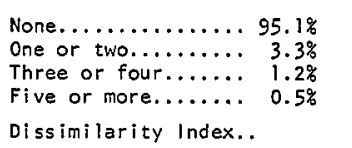

$\begin{array}{cc}0.0 \% & 52.1 \% \\ 76.7 \% & 28.7 \% \\ 14.0 \% & 13.8 \% \\ 9.4 \% & 5.3 \% \\ 95.1 & 42.9\end{array}$

$\begin{array}{ccc}94.6 \% & 0.0 \% & 65.1 \% \\ 2.9 \% & 78.3 \% & 25.3 \% \\ 1.5 \% & 12.5 \% & 6.6 \% \\ 0.9 \% & 9.1 \% & 3.0 \% \\ & 94.6 & 29.6\end{array}$

Educational Level of Household Head

\begin{tabular}{|c|c|c|c|c|c|}
\hline 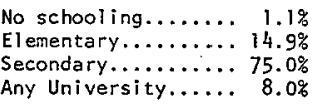 & $\begin{array}{l}1.5 \% \\
8.6 \% \\
76.0 \% \\
13.9 \%\end{array}$ & $\begin{array}{l}0.0 \% \\
7.7 \% \\
67.5 \% \\
30.8 \%\end{array}$ & $\begin{array}{r}0.8 \% \\
9.4 \% \\
74.1 \% \\
15.7 \%\end{array}$ & $\begin{array}{l}0.6 \% \\
7.4 \% \\
66.8 \% \\
25.2 \%\end{array}$ & $\begin{array}{l}1.6 \% \\
7.4 \% \\
52.0 \% \\
38.9 \%\end{array}$ \\
\hline Dissimilarity Index... & $6.3^{\circ}$ & 21.9 & & 9.5 & 24.1 \\
\hline
\end{tabular}

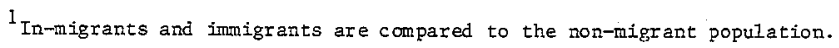
*Difference between proportions statistically significant at the .05 level or less
using a z-test.
}

occupation, education, and marital status dimensions than the immigrant group. It is likely that these dissimilarity indices are lower because of the tendency of retired farmers to migrate to local communities. The characteristics of older, retired farm populations are likely to be similar to those of the local community residents. The notable finding for the smaller communities is that the immigrant group is significantly different from the non-migrant population in all of the characteristics examined.

To further elaborate on the differences between the non-migrant, in-migrant, and immigrant populations of the smaller community, the age and sex distribution for the three migrant statuses are presented in Table 3 and Figure 1. It is markedly evident that the older age structure of the non-migrant population in the smaller communities is in 
Wayne W. McVey, Jr.

TABLE 3. AGE AND SEX DISTRIBUTION BY MIGRATION STATUS' FOR COMMUNITIES UNDER 30,000 POPULATION SIZE, ALBERTA: 1971

\begin{tabular}{|c|c|c|c|c|c|c|c|c|c|c|c|c|}
\hline \multirow{3}{*}{ Life Cycle Stage } & \multicolumn{4}{|c|}{ Non-migrants } & \multicolumn{4}{|c|}{ Migrants } & \multicolumn{4}{|c|}{ Immigrants } \\
\hline & \multicolumn{2}{|c|}{ Male } & \multicolumn{2}{|c|}{ Female } & \multicolumn{2}{|c|}{ Male } & \multicolumn{2}{|c|}{ Female } & \multicolumn{2}{|c|}{ Male } & \multicolumn{2}{|c|}{ Female } \\
\hline & $\#$ & $\%$ & $\#$ & $\%$ & $\#$ & $\%$ & $\#$ & $\%$ & $\#$ & $\%$ & $\#$ & $\%$ \\
\hline All Ages & 84,100 & 48.7 & 88,500 & 51.3 & 44,600 & 53.7 & 38,500 & 46.3 & 4,500 & 47.9 & 4,900 & 52.1 \\
\hline \multirow{5}{*}{$\begin{array}{l}\text { Childhood } \\
5-14 \text { Years } \\
\text { Youth } \\
15-24 \text { Years } \\
\text { Eariy Maturity } \\
25-44 \text { Years } \\
\text { Late Maturity } \\
45-64 \text { Years } \\
\text { EIderly }\end{array}$} & 22,300 & 12.9 & 20,400 & 11.8 & 10,800 & 13.0 & 10,800 & 13.0 & 600 & 6.4 & 500 & 5.3 \\
\hline & 15,200 & 8.8 & 13,300 & 7.7 & 8,700 & 10.5 & 9,300 & 11.2 & 1,000 & 10.6 & 1,100 & 11.7 \\
\hline & 17,300 & 10.0 & 21,700 & 12.6 & 16,700 & 20.1 & 11,500 & 13.8 & 2,700 & 28.7 & 2,400 & 25.5 \\
\hline & 17,100 & 9.9 & 20,900 & 12.1 & 5,700 & 6.9 & 4,500 & 5.4 & 200 & 2.1 & 800 & 8.5 \\
\hline & 12,200 & 7.1 & 12,200 & 7.1 & 2,700 & 3.2 & 2,400 & 2.9 & 0 & 0.0 & 100 & 3.1 \\
\hline
\end{tabular}

IStatistics Canada reports migration status for persons five years old and over only.

SOURCE: Population Research Laboratory, Untversity of Alberta. 1971 Census of Canada, Public Use Sample Tapes, Ind Ividual File.

sharp contrast to the younger age structures of the in-migrant and immigrant populations. The non-migrant group has an aging population pyramid, and the immigrant group reveals a younger age pyramid with a high proportion of its population in the early maturity stage of the life cycle. The in-migrant group also manifests a younger age structure; the older ages (65 years of age and over), however, are well represented. The older age groups in the in-migrant population would be consistent with the movement of retired farmers to local communities.

The largest proportion of the immigrants and in-migrants are in the early maturity stage of the life cycle, with 54.2 and 33.9 per cent, respectively. This accounts for 33,300 in-migrants and immigrants of working age in the smaller communities. The balance shifts in the direction of the male in-migrant and immigrant, with 19,400 as opposed to 17,300 non-migrants in these working ages.

Examination of the sex composition of the three study populations reveals a predominantly male in-migrant group with a sex ratio of 115.8 as compared to the non-migrants and immigrants with sex ratios of 95 and 91.8 , respectively. It is evident that the high sex ratio of 145.2 in the in-migrant early maturity age group has influenced the study population sex differentials. While the immigrant population has a relatively high sex ratio of 112.5 in the early maturity age group, the non-migrant sex ratio of 79.7 indicates a deficiency in the number of males. For the immigrant group, the excess of females in the older age categories offsets the excess of males in the early maturity ages. It is more likely that the immigrant migrates with his family than does the in-migrant.

\section{Discussion}

As revealed in the migration literature, selectivity of in-migrants and immigrants on educational level, occupational status, family size, and marital status was expected for both community size categories. Immigrants and in-migrants to smaller communities showed a marked difference in characteristics when compared to the non-migrants. As indicated, the immigrants to the smaller community is the most dissimilar group. If these 


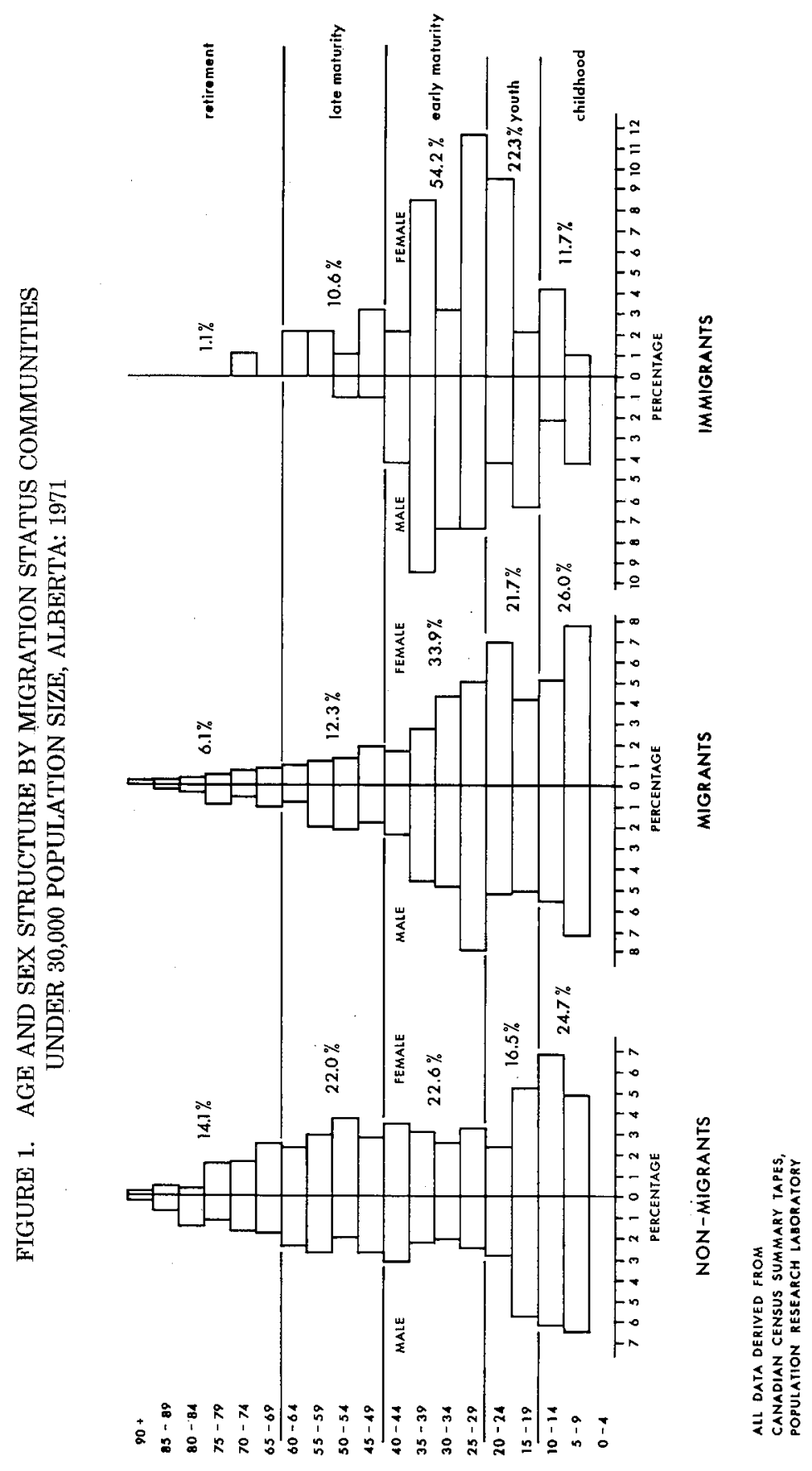


Wayne W. McVey, Jr.

data are indicative of the future character of in-migrant and immigrant migration streams to the smaller community, there may be consequences for the receiving communities in terms of migrant adjustment problems, employment and occupational competition, and unanticipated demands upon housing and social and community services. Strains upon the existing social structure may result when the migrant confronts the task of adjusting to the new community, while the receiving community and its older population will have to accommodate and adapt to the newcomer. The ability of the smaller community's social organization to adjust to a changing population composition will be increasingly important to present and future decentralization policy formulation.

The impact of migration will vary from community to community. However, this variation is concealed by using an aggregate of all communities with less that 30,000 inhabitants. The small communities in this research were not all equally exposed to migration, i.e., some communities experienced rapid population growth over the census decade while other communities declined in population. The policy implications of migration for the smaller community, as well as the differential effects of migration upon small communities, await further investigation.

\section{Acknowledgment}

The data for this paper came from the 1971 Census of Canada Public Use Sample Tapes which were made available for this research by the Population Research Laboratory, Department of Sociology, University of Alberta. The author gratefully acknowledges the valuable assistance of Mr. George Buse, Department of Geography, in the preparation of computer access programmes and statistical calculations.

Footnotes

1. Migration status descriptions were taken from the Public Use Sample Tape user documentation, dated March, 1975. In-migrants, as used in the text, are classified as migrants in the census field documentation.

2. Age by sex distribution data were retrieved only for the smaller communities because of time and cost constraints. Median age was calculated for the three migration statuses. The median age of the in-migrants and the immigrants were significantly different from the median age of the non-migrants at the 0.5 level or less using the z-test. The z-test is a technique for testing for the possible significance of the observed difference between two sample percentages.

$\begin{array}{cccc} & \text { Non-migrants } & \text { In-migrants } & \text { Immigrants } \\ \text { Median age } & 42.1 & 26.3^{*} & 30.6^{*}\end{array}$

\section{References}

Bogue, D. 1959. Internal Migration. In P.M. Hauser and O.D. Duncan (eds.), The Study of Population. Chicago: University of Chicago Press.

DeJong, G.F., and C.R. Humphrey. 1976. Selected Characteristics of Metropolitan-to-Nonmetropolitan Area Migrants: A Study of Population Redistribution in Pennsylvania. Rural Sociology 41:527-538.

Gertler, L., and R. Crowley. 1977. Changing Canadian Cities: The Next 25 Years. Toronto: McClelland and Stewart Limited.

Goldscheider, C. 1971. Population, Modernization, and Social Structure. Boston: Little, Brown, and Company.

Graber, E.E. 1974. Newcomers and Oldtimers: Growth and Challenge in a Mountain Town. Rural Sociology 39:504-513.

Kalbach, W.E., and W.W. McVey. 1971. The Demographic Bases of Canadian Society. Toronto: McGraw-Hill Company of Canada Limited. 
Kirschenbaum, A. 1971. Patterns of Migration from Metropolitan to Non-metropolitan Areas: Changing Ecological Factors Affecting Family Mobility. Rural Sociology 36:315-325.

Lamont, G.R., and V.B. Proudfoot. 1975. Migration and Changing Settlement Patterns in Alberta. In L.A. Kosinski and R.M. Prothero (eds.), People on the Move: Studies on Internal Migration. London: Methuen and Company, Limited.

Petersen, W. 1969. Population. New York: Macmillan.

Shryock, H.S. 1964. Population Mobility Within the United States. Chicago: University of Chicago, Community and Family Study Center.

Shryock, H.S. and J. Siegel. 1973. The Methods and Materials of Demography. Washington, D.C.: U.S. Government Printing Office.

Stone, L. 1968. Urban Development in Canada. Ottawa: Dominion Bureau of Statistics.

1969. Migration in Canada: Some Regional Aspects. Ottawa: Dominion Bureau of Statistics.

, and S. Fletcher. 1977. Migration in Canada, 1971 Census of Canada Profile Studies. Ottawa: Statistics Canada.

United Nations. 1975. Planning for Small Communities, Report on the Red Deer Symposium sponsored by the Canadian Habitat Secretariat. Edmonton: Federal and Intergovernmental Affairs Department.

Wardell, J.M. 1977. Equilibrium and Change in Non-metropolitan Growth. Rural Sociology 42:156-179.

Received September, 1977; revised March, 1978. 